\title{
UM ENSAIO SOBRE A ASCENSÃO DE DONALD J. TRUMP
} AN ESSAY ON DONALD J. TRUMP'S UPRISE

\section{Thayris de Oliveira ${ }^{1}$ Ariel Finguerut ${ }^{2}$}

Resumo: A proposta deste ensaio é discutir a ascensão de Donald J. Trump, suas ideias, estratégias políticas fazendo uma análise tanto de conjuntura doméstica como seus impactos na projeção internacional dos Estados Unidos. Neste caminho discutimos conceitos como a polarização política, o populismo, a pós-verdade e a manipulação do medo especialmente contra o islã.

Palavras-chave: Donald J. Trump; Populismo nos EUA; Pós-Verdade; Islã
Abstract: The purpose of this essay is to discuss the rise of Donald J. Trump, his ideas, and political strategies by analyzing both the domestic context and its impact on the international projection of the United States. In this line we discuss concepts such as political polarization, populism, post-truth and the manipulation of the fear especially against Islam.

Key-words: Donald J. Trump; Populism in the USA; Post-Truth; Islam.

\section{1a Parte - A Ascensão: Não é piada; é Donald J. Trump}

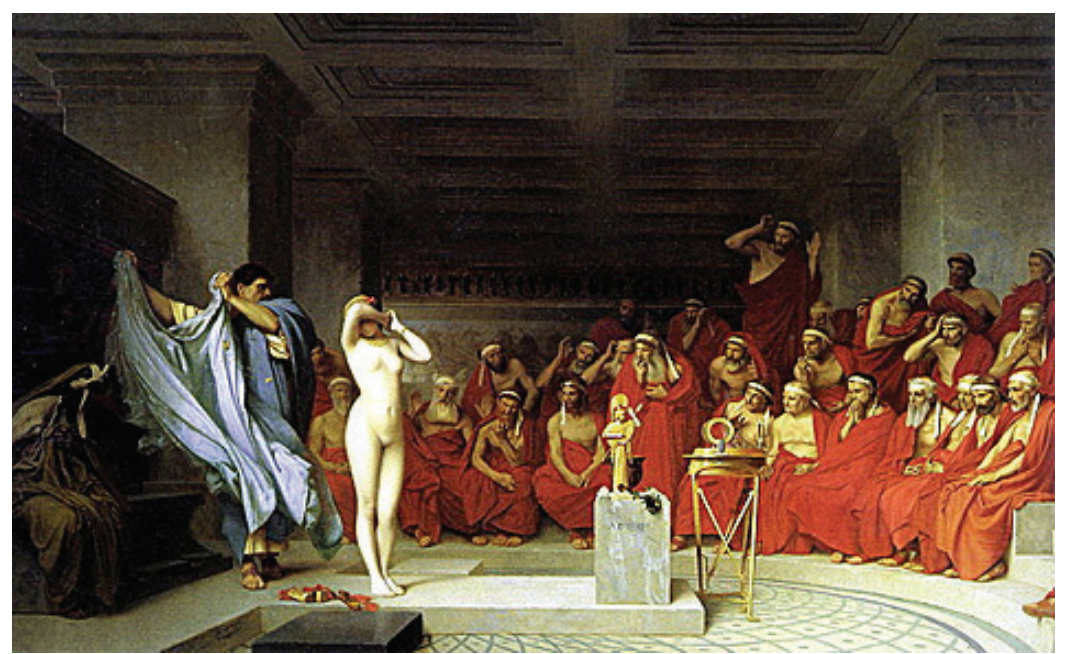

Jean-Léon Gérôme, Phryné devant l’Aréopage³, 1861.

Em 16/06/2015 Trump ao lado de outros 16 nomes lançou-se como candidato nas primárias do partido Republicano. Apresentando-se como "empresário", "homem

\footnotetext{
${ }^{1}$ Graduada em Relações Internacionais pelo Centro Universitário Senac, São Paulo. Link para o Currículo Lattes: http://lattes.cnpq.br/9872152571973114.Contato: oliveirathayris@gmail.com

${ }^{2}$ Doutor em Ciência Política pela Unicamp, pesquisador do Projeto Sem Diplomacia (UNESP, San Tiago Dantas e Acessória de Imprensa da UNESP) e o Grupo de Trabalho Oriente Médio Mundo Muçulmano (GT OMMM) da Universidade de São Paulo (USP). Agradeço a oportunidade de ter debatido "Donald Trump" com interlocutores tão privilegiados como Solange Reis, Roberto Moll e Luis Fernando Ayerbe do Projeto Sem Diplomacia, Peter R. Demant do GT Oriente Médio Mundo Muçulmano, Nick Loris do HeritageFoudantion e Thayris de Oliveira, parceira desta texto. Link para o Currículo Lattes: http://lattes.cnpq. br/3515075741483144. Contato: arielfing@gmail.com

${ }^{3}$ Acervo da Kunsthalle Hamburg.
} 
de negócios" e como bilionário ${ }^{4}$. Não era um candidato conservador, tanto que se quer participou em setembro de 2015 do Values Voter Summit ${ }^{5}$ no qual na escolha dos participantes ficou em quarto lugar com $5 \%$ das preferências como o candidato favorito. Trump já tinha ensaiado uma pré-candidatura em 2012 e na época sua principal plataforma de campanha era a tese do birtherism - ideia de que o presidente dos Estados Unidos da América (EUA), Barack H. Obama em meio a uma rede de conspirações, não nasceu nos EUA e, portanto, seria um presidente ilegítimo. Trump teve passagem rápida pelas primárias de 2012 mesmo assim, e ao sair da disputa em sua declaração oficial afirmava estar diante de uma "escolha difícil", pois tinha certeza que iria ganhar as primárias e a disputa nacional ${ }^{6}$, mas ainda não estava "pronto" para deixar seus negócios.

Entre 2012 e 2015 Trump não teve protagonismo político e sua recepção nas primárias republicanas principalmente entre os candidatos favoritos era deboche e incredibilidade. Trump seria apenas uma "celebridade" querendo atenção para seu próximo reality show. Os birthers destacavam-se nos primeiros comícios questionando o candidato sobre o que fazer diante de uma "islamização em massa em curso nos EUA". Trump não negava nem confrontava este fiel eleitorado nativista, mas passou a adotar outra estratégia sustentada claramente num tripé de teses: 1) o Nacionalismo Econômico 2) Intervenção estatal na política migratória (controle e securitização das fronteiras) 3) Uma Política Externa mais nacionalista e menos interdependente.

Com esta plataforma Trump se diferenciou de sua imagem de 2012 (mais conspiratória e que flertava com movimentos nativistas, milicianos e de extrema direita); tal como se diferenciava dos candidatos conservadores clássicos que defendiam menos intervenção estatal (cortes de impostos) com a defesa do liberalismo econômico na política externa e uma agenda conservadora nos temas sociais (como aborto, mudança climática, casamento gay etc.). Um passo seguinte para Trump foi enfatizar suas credencias de "homem de negócios" e de "empresário bem sucedido" para colocar políticos republicanos do establishment na defensiva.

Trump conseguiu colocar todos os seus 16 concorrentes numa situação "incomoda" e diante de uma agressividade inédita num partido conservador como o Republicano, o bilionário destacou-se e conseguiu deslanchar sua candidatura a partir do debate na Fox News realizado no dia 06 de agosto de $2015^{7}$. A partir deste evento, Trump passou a ser o candidato que polarizava o debate. Suas intervenções, comentários ou simplesmente olhares e expressões serviam de munição para um eleitorado que passou a enxergar em Trump uma espécie de "voz do povo" contra as elites e contra o establishment conservador e liberal.

\footnotetext{
${ }^{4}$ Supostamente com fortuna de 9 bilhões de dólares embora isso nunca foi provado e sequer sabe-se quanto Trump paga e declara ao Imposto de Renda dos EUA.

${ }^{5}$ Trata-se de um evento anual organizado pelas principais organizações, grupos e fundações conservadoras dos EUA.

6 Cf. Declaração oficial em <http://blogs.abcnews.com/thenote/2011/05/trump-not -runninng-for-president.html> Acessado em 12/12/2016.

${ }^{7}$ Cf. Debate na integra em <https://www.youtube.com/watch?v=2rU4W3yfd58> Acessado em 14/12/16.
} 
Em 21/08/15 Trump reuniu cerca de 30 mil pessoas num evento de campanha no estádio Ladd-Peeblesem Mobile no estado sulista do Alabama. As pessoas estavam ali não por serem conservadoras nem por serem republicanas, nem tão pouco para protestar contra Obama ou Hillary Clinton ou qualquer outra coisa a não ser para ver, ouvir e aplaudir por alguns minutos, Donald Trump. Depois de Mobile, ficou claro como seria o Trump candidato. Suas falas seriam relativamente curtas, sem perguntas nem roteiro prévio, sua ênfase e foco seriam "falar o que pensa" e a retórica nacionalista daria o tom, hora com ênfase na crise econômica nacional, hora com ênfase nas "desvantagens" e perdas de emprego que a política externa "internacionalista" e "cosmopolita" estava produzindo para os EUA. Em meio a este processo Trump também se colocava como um outsider da política tradicional - um candidato anti-sistema - ao mesmo tempo que se dizia como um “jogador/negociador experiente” do capitalismo e do mundo dos negócios, se negava a ser um político, como eram todos os seus concorrentes.

O primeiro alvo de Trump foi o candidato mais significativamente do establishment dentre os 16 pré-candidatos republicanos: Jeb Bush. Trata-se de candidato emblemático. Ex-governador da Flórida, entre 1999 e 2007, um swing state central para os estrategistas republicanos, considerado um político popular - historicamente mais popular que seu irmão George W. Bush. Jeb era até o primeiro semestre de 2015considerado o favorito para 2016. Em julho de 2015, Jeb liderava e atingia 20\% na média das pesquisas contra os demais republicanos e sinaliza para uma presidência parecida com de seu irmão do Texas. Jeb Bush em meio a ataques diretos de Trump perdeu força rapidamente e a aposta do establishment rapidamente migrou para Marco Rubio.

O jovem senador da Flórida tinha como um lema de campanha A New American Century, que fazia referência clara aos anos George W. Bush. Rubio passou a ser a aposta de muitos neoconservadores como William Kristol, Robert Kagan e Elliot Abrams. E como tal passou também a ser alvo da ira e dos ataques direitos de Donald Trump.

Ao escolher como antagonistas a dupla Bush/Rubio ambos próximos aos neoconservadores, surgiu em círculos intelectuais como da The Weekly Standard, um movimento que visava unir os conservadores contra Trump e impedir sua vitória nas primárias republicanas. 0 slogan da iniciativa inicialmente era "Neither Trump nor Hillary" e a ideia era buscar uma alternativa entre a já aparente polarização entre um candidato que não seria conservador contra um candidato que poderia ser um pesadelo para a direita americana. 0 movimento não cresceu, ao contrário, as primárias republicanas rapidamente tornaram-se "sobre Trump"; forçando estes intelectuais conservadores a focarem em uma nova campanha, agora totalmente anti-Trump, com o slogan "\#NeverTrump". A ideia era evitar por todos os meios, mesmo que fosse necessário apoiar Hillary Clinton, uma vitória de Trump.

Sem o apoio do establishment conservador, mas principalmente sem um respaldo e uma assessoria destes conservadores, Trump rapidamente encontrou apoio na chamada alt right e, na medida em que crescia nas pesquisas, muitos que juravam "neverTrump" passaram a jurar apoiá-lo. E o candidato bilionário percebeu que parte do eleitorado o 


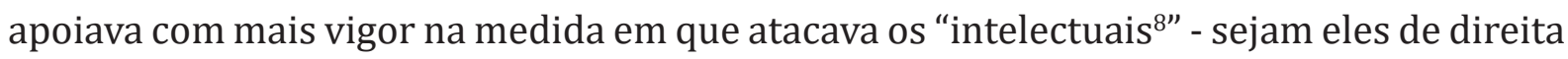
ou de esquerda.

\section{2ª Parte - 0 que propõe Trump? Uma mentira repetida até virar pós-verdade.}

"Será da própria essência da verdade ser impotente e da própria essência do poder enganar?" Hannah Arendt ${ }^{9}$

O empresário americano Donald J. Trump destacou-se como candidato à presidência dos Estados Unidos em 2016. Representando o Partido Republicano, chamou a atenção por demonstrar segurança a ponto de fazer afirmações e acusações tanto à direita quanto à esquerda, baseadas em especulações, sem ter base para corroborá-las. Apesar de seu discurso atípico - tido por muitos como protecionista, retrógrado, racista, xenofóbico e machista - Trump venceu as eleições e tornou-se o 45a presidente estadunidense. Para alguns críticos, o republicano representa o "principal expoente da política pós-verdade", uma política que ao invés de ser fundamentada em fatos concretos, apoia-se em opiniões sem fundamentos. 0 conceito de "pós-verdade" - em inglês: "post-truth" - remete à ideia de que em determinadas circunstâncias, os fatos objetivos são menos influentes na formação da opinião pública do que os apelos às emoções e crenças pessoais ${ }^{10}$. Em outras palavras, demonstra que as sensações e convicções individuais são mais relevantes à opinião pública do que a veracidade dos acontecimentos.

Não é novidade que na esfera política, no que diz respeito à lógica das decisões políticas, a opinião da maioria - independente de ser verdadeira ou não -possui mais relevância do que a verdade (ARENDT, 1967; BAGGIO, 2000). Segundo Baggio (2000) isso acontece porque se diversas partes lutassem, cada uma em nome da verdade (que não admite comedimentos), as contendas seriam insolúveis e absolutas. Nesse sentido, ao levar em consideração a (vontade da) maioria, evita-se o conflito violento, ou seja, a lógica das decisões políticas exclui a preocupação com a verdade porque dessa forma é garantida a ordem em determinado corpo social. Nesse contexto, admite-se o sacrifício da verdade em nome da sobrevivência do corpo político (ARENDT, 1967). Ademais, Arendt (1967) complementa indicando que a mentira é tida como um recurso inofensivo da ação política, visto que é um meio para impedir a ação violenta.

Por outro lado, a mentira também é utilizada como recurso para que determinado ator político, em prol de seus interesses, possa manipular a perspectiva de certo grupo em relação à realidade, isto é, possui a finalidade de fazer com que opinião expressa por uma parte seja aceita pela maioria como fato real. Com intuito de melhor elucidar

\footnotetext{
${ }^{8}$ Este foi o teor de um texto opinativo escrito por Trump para o Wall Street Journal em 14/04/2016. Cf. Texto em <http://www.wsj.com/articles/let-me-ask-america-a-question-1460675882>. Acessado em $14 / 12 / 2016$.

${ }^{9}$ Cf. Verdade e Política em <http://abdet.com.br/site/wp-content/uploads/2014/11/Verdade-e-pol\%C3\%ADtica.pdf/ > Acessado em 15/01/17.

${ }^{10} \mathrm{Cf}$. Word of the Year 2016 is (...) em< https://en.oxforddictionaries.com/word-of-the-year/word-of-the -year-2016 >Acessado em 16/01/17.
} 
estas constatações, seguem dois trechos que demonstram como a mentira é utilizada na dinâmica política:

Se concebermos a ação política em termos de meios e de fins, podemos mesmo chegar à conclusão, só na aparência paradoxal, que a mentira pode muito bem servir para estabelecer ou salvaguardar as condições da procura da verdade - tal como há muito assinalou Hobbes, cuja lógica implacável nunca deixa de levar os argumentos para esses extremos em que o seu absurdo se torna evidente. E as mentiras, precisamente porque são muitas vezes utilizadas como substitutos de meios mais violentos, podem facilmente ser consideradas como instrumentos relativamente inofensivos do arsenal da ação política (ARENDT, 1967, pg. 4)

Que os políticos às vezes vendem mentiras não é novidade: pense na mentira de Ronald Reagan de que seu governo não havia trocado armas com o Irã para garantir a libertação de reféns e financiar os esforços dos rebeldes na Nicarágua. Ditadores e democratas que buscam desviar a culpa por sua própria incompetência sempre manipularam a verdade; os perdedores sempre acusaram o outro lado de mentir (THE ECONOMIST, 2016) ${ }^{11}$.

Contudo, quando analisamos o fenômeno da pós-verdade percebemos que os fatos concretos não são adulterados, porém, são ignorados em certas situações, visto que o indivíduo considerará algo como legítimo de acordo com a sua percepção sobre o que acredita ser verdade mais do que pelo que a realidade revela ${ }^{12}$. Assim, constatamos que a verdade - pautada em valores tangíveis - adquire uma importância secundária já que para o indivíduo serão os pontos de vista/crenças que determinarão seu posicionamento em relação a algum acontecimento social ${ }^{13}$.

A fim de exemplificar a ideia exposta no parágrafo anterior, citaremos com exemplo o episódio que Trump acusa Barack Obama de adulterar documentos para se passar por americano. A "denúncia" do republicano estaria embasada em alguns pontos "suspeitos" da vida de Obama, tais como: a nacionalidade de seu pai não ser a estadunidense (seu pai era queniano, de fato), nome e sobrenome pouco comuns aos americanos, e por fim, ter vivido na Indonésia por um período considerável. Obama, por sua vez, apresentou sua certidão de nascimento para refutar tal acusação, dessa maneira, comprovou a legitimidade de sua nacionalidade. Apesar disso, Trump continuou defendendo a sua opinião, alegando que sentia - tal como outras pessoas - que a prova do democrata não era verdadeira. Verifica-se que esta situação indica que, embora não haja comprovação da

\footnotetext{
${ }^{11}$ Trecho original em inglês: That politicians sometimes peddle lies is not news: think of Ronald Reagan's fib that his administration had not traded weapons with Iran in order to secure the release of hostages and to fund the efforts of rebels in Nicaragua. Dictators and democrats seeking to deflect blame for their own incompetence have always manipulated the truth; sore losers have always accused the other lot of lying (THE ECONOMIST, 2016).

${ }^{12}$ Pode-se citar como exemplo, a cerimônia de posse presidencial de Donald Trump. Nesta, Trump e sua equipe afirmar que este acontecimento fora o "maior evento da história". No entanto, o quórum fora menor em comparação a posse de Barack Obama. Diante das contestações, a equipe de Trump admitiu que suas afirmações baseavam-se em "fatos alternativos" . Cf. Donald Trump's team now says "biggest inauguration ever' claim is based on 'alternate facts' em http://www.mirror.co.uk/news/world-news/white-house -war-media-row-9674537Acessadoem 28/01/2017.

13 Cf. The Truth about "Post-Truth"em<http://www.cbc.ca/radio/ideas/the-truth-about-post-truth $-1.3939958>$ Acessadoem 28/01/17.
} 
convicção pessoal, a mesma se sobressai ao dado concreto porque os indivíduos tendem a interpretá-la como algo real. Com isso, vê-se que quando a evidência de uma crença é bem articulada, o indivíduo tende a considerá-la como algo legítimo sem levar em consideração a sua veracidade.

Trump é considerado com símbolo da política pós-verdade porque se utilizou, demasiadamente, das especulações durante a sua candidatura. Um fator que contribuiu para sua campanha foi a internet (especialmente, as redes sociais) porque promoveram a disseminação de suas ideias, além de aproximá-lo do eleitorado. Entretanto, sabe-se que o tipo de notícia baseada em especulações, ou melhor, no conceito de pós-verdade tem a sua credibilidade comprometida. Por outro lado, desperta o interesse do público e isso pode resultar certa lucratividade ao meio de comunicação e votos nas eleições.

A internet promove a pós-verdade porque as notícias que são compartilhadas online dentro de um universo virtual/digital - cujos membros lhe dão mais credibilidade do que para qualquer outra fonte - podem assumir a aparência de serem verdadeiras e plausíveis, assim, constata-se que se perde a preocupação com a veracidade das notícias desde que estas façam sentido ao contexto do qual o indivíduo está inserido. Além disso, a fragmentação de fontes de informação resulta em um mundo atomizado no qual as afirmações sem embasamento propagam-se facilmente e com velocidade.

De acordo com Canavilhas (2009), a escala e a proximidade são as duas grandes vantagens do "universo online" porque se tratam de condições caras aos políticos. Kerbel (apud CANAVILHAS, 2009) afirma que a aposta dos políticos nestas ferramentas tem por base a ideia de que o acesso virtual funciona tanto quanto o acesso real e isto, em larga escala, tende a transformá-lo em um dispositivo mais eficaz do que os meios tradicionais (jornais e telejornais), pois possibilita codificar a mensagem em diversos formatos (multimedialidade), possui uma abrangência global (ubiquidade) e favorece a personalização da informação permitindo que o comunicador tenha a sensação de que é ele que controla todo o processo (interatividade), escapando do controle dos meios tradicionais (CANAVILHAS, 2009). Segundo Carlson e Djupsund (2001) o comunicador tem pleno controle sobre a mensagem, pois a internet não lhe impõe nenhuma censura ou faz algum filtro, ou seja, a mensagem que é transmitida ao destinatário supera o processo de edição jornalística. Abaixo segue um exposto que auxilia na compreensão aqui apresentada:

(...) a internet é potencialmente interativa, isto é, torna-se possível um diálogo de mão dupla entre quem envia e quem recebe. Terceiro, o novo meio provê àquele que envia um recurso relativamente barato para transmitir grandes volumes de informação. Finalmente, a técnica sofisticada da comunicação via Web dá ao comunicador uma ampla gama de possibilidades donde escolher a forma da comunicação (texto, imagens, som e vídeo) considerada mais apropriada para uma mensagem particular. Em conclusão, a Web provê os agentes políticos com a oportunidade pela qual ansiava, isto é, a de ter controle total sobre a produção da mensagem e comunicar diretamente com os potenciais eleitores sem ter os meios de massa filtrando-lhe a informação (Carlson e Djupsund, 2001, p. 69). 
No caso, Trump apostou numa campanha baseada no medo, apresentando a si mesmo com a única solução imediata aos problemas americanos ${ }^{14}$. Não obstante, o empresário estadunidense enfatizou que seu objetivo é fazer com que os EUA recuperem seu prestígio no campo econômico e militar - enfraquecido pelos governos anteriores assim como combater o terrorismo e a violência causada pela imigração ilegal ${ }^{15}$. Neste ponto, fez inúmeras acusações contra a sua oponente Hillary Clinton e ao seu partido Democrata - indicando que estavam compactuando contra a nação americana ${ }^{16}$.

A postura de Trump tem lhe rendido severas críticas, muitos estão convencidos de que a sua vitória anuncia a imposição de um autoritarismo putinesco ou até mesmo o fascismo total, considerando que durante a campanha presidencial utilizou-se de um discurso distópico: prometeu restaurar a "ordem"; incitou casualmente a violência, prometeu "prender" sua oponente democrata; recusou-se a divulgar suas declarações de imposto de renda; propôs proibir os muçulmanos de entrarem nos EUA e restituir o uso da tortura nas estratégias americanas de combate ao terrorismo ${ }^{17}$. Além de desdenhar, desqualificar e ridicularizar seus oponentes e críticos, colocando-se acima das leis e questionando as instituições. Como sintetiza texto da revista The New Yorker:

Ele é Trump, mas isso, em si, apresenta um perigo real. Tudo sobre ele sugere que, quando ele entrar na Casa Branca, ele continuará alegremente transgredindo as normas democráticas, censurando seus oponentes, jogando fora falsidades flagrantes e buscando explorar sua posição para ganho pessoal. Isso é o que ele faz. Se alguma coisa, o isolamento e as pressões do Salão Oval pudessem distorcer ainda mais seu ego e exagerar suas tendências ditatoriais (CASSIDY, 2016) ${ }^{18}$.

Se por um lado, sua figura gera sérias preocupações, por outro, não são poucos os que o apoiam. Para os apoiadores, Trump não demonstra medo, fala e apresenta situações como elas supostamente realmente são; mostra-se como um líder capaz de detectar e solucionar os reais problemas do país, como o terrorismo e a criminalidade ${ }^{19}$, por exemplo. Sua campanha conseguiu atrair um eleitorado mais amplo que o conservadorismo (já historicamente próximo dos Republicanos), flertando com o eleitorado radical - antiimigrante, antissemita, islamofóbico e nacionalista, mas também que ecoou com êxito numa base mais próxima aos democratas, de trabalhadores de classe média baixa, branco

\footnotetext{
${ }^{14}$ Cf. 0 risco Trump em < http://epoca.globo.com/tempo/noticia/2016/07/o-risco-trump.html> Acessado em 15/01/17.

${ }^{15}$ Cf. Discurso de Donald J. Trump em <https://www.youtube.com/watch?v=gYQB7mHuREs > Acessado em $15 / 01 / 17$.

${ }^{16}$ Cf. Donald Trump Is Building a Team of Fake-News Lovers and Conspiracy Theorists em< http://www. motherjones.com/politics/2016/12/trump-fake-news-michael-flynn-pizzagate>Acessadoem 15/01/17.

17 Cf. Trump's challenge to American Democracy em<http://www.newyorker.com/news/john-cassidy/ trumps-challenge-to-american-democracy>Acessadoem 15/01/17.

${ }^{18}$ Trecho original em inglês: He's Trump, but that, in itself, presents a real danger. Everything about him suggests that when he enters the White House he will continue gleefully transgressing democratic norms, berating his opponents, throwing out blatant falsehoods, and seeking to exploit his position for personal gain. That's what he does. If anything, the isolation and pressures of the Oval Office might further warp his ego and exaggerate his dictatorial tendencies (CASSIDY, 2016).

${ }^{19}$ Cf. Como a guerra ao 'politicamente correto' explica ascensão de Trump em < http://www.bbc.com/portuguese/noticias/2016/03/160303_politicamente_trump_jf> Acessado em 15/01/17.
} 
e com poucos anos de estudo - cuja renda diminuiu consideravelmente nas últimas décadas em decorrência da crise econômica de 2008, bem como da migração de empregos para outros países. Ao proclamar-se como "porta-voz" do povo, o empresário conquistou eleitores que se sentiam negligenciados pelo sistema e deixados para trás pela elite ${ }^{20}$.

A eleição de Trump evidencia uma polarização e uma divisão entre os americanos. Nota-se que os eleitores democratas eram aqueles que residiam, principalmente, nas grandes cidades, com nível educação superior e se opõem a um conservadorismo social. Já os republicanos concentravam-se mais nas zonas rurais, sem educação de nível superior e que eram mais conservadores. Observa-se também que Hillary Clinton recebeu maior apoio por parte dos afro-americanos, hispânicos, jovens e mulheres, enquanto Donald Trump deteve a preferência da população com mais 65 anos de idade, especialmente, entre os homens (teve $63 \%$ dos votos). Embora já houvesse polarização em eleições anteriores (o fenômeno é estudado como "fato político" desde as eleições de 1992), Trump mantinha-se firme em suas declarações, de modo que promoveu e levou a mentalidade de polarização - a ideia de "nós vs. eles" - a novos níveis alimentando conspirações e não qualificando discursos nem aliados ${ }^{21}$. Neste contexto, vale mencionar que fez oposição até aos membros e figuras importantes de seu próprio partido como: Paul Ryan, Marco Rubio, Ted Cruz, Chris Christie e Ben Carson. Ao agir desta maneira, apresentou-se como uma nova força ao partido que, na sua visão, estava fragilizado. Fez com que muitos desacreditassem da imprensa, acusando-a de favorecer a candidata democrata e de atacá-lo ferozmente devido as suas propostas de governo. As mídias contribuíram consideravelmente para o fortalecimento de sua campanha, conforme a citação abaixo:

Donald Trump não parece ser um político de muitas convicções. Mas é um hábil populista: sente na veia o que seu público quer ouvir e faz o discurso no tom certo, com o vocabulário adequado, e a mensagem precisa.

Enquanto, na televisão, para o público geral, seus discursos pareciam por vezes até grotescos, em um nicho do público se encaixavam como luva.

(...) O resultado é que, no dia de uma eleição vencida por margens muito estreitas, Hillary havia conseguido animar os eleitores naquele nível padrão de outros tempos. Trump, não. Trump teve eleitores leais como só na internet se é possível criar (DORIA, 2016) 22 .

É interessante perceber que um dos aspectos notórios na eleição de Trump, foi expor a ideologia e a falácia, em diferentes dimensões, de uma significativa parcela de jornalistas e intelectuais sejam liberais/de esquerda, sejam conservadores/de direita. Estes, por sua vez, têm reagido ao resultado como se o republicano estivesse fazendo algo novo: mentir e especular na lógica política, relacionando-o como símbolo da pós-verdade ${ }^{23}$

\footnotetext{
${ }^{20}$ Cf. Eleições nos EUA: Cinco razões para vitória de Trump em < http://www.bbc.com/portuguese/internacional-37923743> Acessado em 15/01/17.

${ }^{21}$ Cf. Post truth: Art of the Lie em< http://www.economist.com/news/leaders/21706525-politicians-havealways-lied-does-it-matter-if-they-leave-truth-behind-entirely-art>Acessadoem 15/01/17.

22 Cf. Donald Trump e a pós-verdade em <http://oglobo.globo.com/economia/trump-a-pos-verdade-20484416> Acessado em 15/01/17.

${ }^{23}$ Cf. DonaldTrump e a "política da pós-verdade"em<http://www.gazetadopovo.com.br/opiniao/colu-
} 
ou denunciam o "anti-intelectualismo". A estratégia de Trump é desqualificar os críticos, como na fábula The Boy Who Cried Wolf, o bilionário instiga seus eleitores a não acreditar mais naqueles que "gritam lobo" a toda hora e por qualquer coisa. Quando precisa se justificar ou quando é confrontado com fatos, Trump e sua equipe apoiam - se em fatos alternativos, sejam eles da chamada alt right, seja através do conceito de pós-verdade, apelando para as emoções, buscando assim uma comunicação cujos fatos e a veracidade é pouco relevante. Desta forma Trump revela-se um populista e explora os sentimentos dos americanos que se consideravam prejudicados ou que se sentiam distantes das promessas do sonho americano e mesmo quando declara a mídia como "inimiga", faz seu jogo, ao estilo de um reality show.

A pós-verdade demonstra que a pulverização de informações, todo informação disponível online - em toda sua infinitude - não é suficiente para criarmos atores políticos plenamente racionais, bem informados, prontos para fiscalizar e confrontar seus governantes. Trata-se de um sintoma da chamada "economia da atenção ${ }^{24 "}$

Trump como presidente representa e reafirma uma tradição política já apontava sociólogos como Richard Hofstadter nos anos de 1960, própria do nativismo ${ }^{25}$ e do antiintectualismo ${ }^{26}$ se alimentam da mesma tradição política que Alexis de Tocqueville, em toda sua desconfiança, apontava florescer a democracia liberal. 0 cientista política Charles Murray, um conservador, a pelo menos 20 anos, aponta os riscos e os impactos políticas das chamadas "bolhas ${ }^{27 "}$ que formam e distorcem a sociedade americana contemporânea. As bolhas não são apenas na comunicação - mídia conservadora, mídia liberal, mídia alternativa, mídia de entretenimento, mídia política, jornais econômicos, jornais sensacionalistas, publicações acadêmicas etc. - e chegam a todos os campos. Há bolhas demográficas, econômicas, de diferenciação de gostos, de distinção social, comportamentos políticos etc. Trump "divide para conquista", "ataca para se defender" e fala sem medir a consequência de suas palavras, com todo "poder de tsunami" que um tweet ${ }^{28}$ possa ter.

Trump soube com êxito conquistar a atenção da opinião pública e consequentemente do eleitorado americano. Tal feito é fruto de uma manipulação das emoções e de uma retórica populista, explorando as fraquezas de seus aliados e adversários a fim de convencer o povo americano que ele era o melhor candidato, criando a ilusão de que não era um

nistas/bruno-garschagen/donald-trump-e-a-politica-da-pos-verdade-dakbk0mjfr62ka408bm407snh37923743> Acessado em 15/01/17.

${ }^{24}$ Conceito do filosofo suíço, Yves Citton que argumenta no contexto do avanço da economia digital e do tempo que gastamos socialmente em realidades virtuais, no qual há uma superabundância de informações e estimulas, nossa "atenção" é o bem mais valiosos e ele que as grandes empresas e todo aparato de "rastreamento virtual" se sustenta como negocio lucrativo. Em outras palavras, lucra quem consegue mais atenção. ${ }^{25}$ A referência clássica para Hofstadter neste caso seriam movimentos como o Ku Klux Klan nos anos de 1920 e 30. Cf. HOFSTADTER (1966).

${ }^{26}$ Neste caso a referencia clássica seria a candidatura derrotada do senador do Arizona, Barry Goldwater em 1964. Cf. HOFSTADTER (1964).

${ }^{27}$ Cf. Coming Apart, 2013, Ed. Crown Forum. NYC.

${ }^{28}$ Sobre o papel e o impacto social do Twitter, Cf. discussão de Christian Rudder, Dataclysm, Ed. Broadway Books; NYC. 2015. 
político e sim um deles, um do povo, uma síntese das aspirações populares. Trump falaria pelos insatisfeitos, pelos patriotas não representados e por um país - uma verdadeira distopia - fragilizado, fraco e sem rumo. 0 empresário americano explorou o campo dos sentimentos, não teve receio de rivalizar, se xingar, ameaçar, conspirar, se colocando hora como "vítima" hora como "salvador da pátria", se colocando sempre como o centro das atenções de tal forma que - querendo ou não - as eleições foram "sobre Trump" e mesmo perdendo ${ }^{29}$, ele ganhou.

\section{3a Parte - Manipulando os medos e encontrando culpados. Misoginia, Racismo e toda a culpa nos imigrantes (mexicanos) e no islã.}

“(...)o populismo é um movimento de pessoas comuns cujos interesses são ignorados em tempos de stress/crise econômica e de transformações (culturais e sociais) Michael Gerson

A ideia de "ser grande novamente" cria um recorte que exclui muitos e inclui alguns no conceito de América. É possível, por exemplo, lembrar a "estratégia sulista” cujo auge foi ocorreu na eleição de Nixon em 1968. A ideia da eleição de Nixon era alienar o voto dos negros e conquistar o voto dos homens brancos sulistas que até então eram eleitores democratas.

Trump tal como Nixon no passado focou sua estratégia no eleitorado que considerada "esquecido" ou excluído da política multiculturalista da base democrata. Nesta base estariam todas as minorias religiosas não cristãs, as mulheres feministas, os negros e latinos. Portanto para a campanha de Trump o fim da esperança é a América destas pessoas (feministas, negros e não cristãos). A ideia de "voltar a ser Grande" remete ao resgate da América excluída e ignorada por esta base política liberal/ multiculturalista.

Neste ponto Trump não se coloca como "conservador" nem "progressista", mas como um movimento no qual nos termos novamente de Gerson: "(ele) ira agir em nome e com a ajuda do povo".

\section{De qual "povo" / folk fala Trump?}

A ideia é resgatar os homens brancos, a base conservadora tradicionalista (cristã) e principalmente alienar o multiculturalismo. Trump não fala diretamente nos temos de Allan Lichtman (2009) de uma América Branca e Protestante, contudo indiretamente enfatiza a ideia que a América volte a ser grande para os Homens, para os Brancos e para os Cristãos. Em outras palavras, Trump mira em "três desigualdades" com três grupos a resgatar e a eles, sim, proporcionar que a "América Volte a ser Grande". Trata-se da desigualdade de classe, de raça e de sexo. Em termos de classe, Trump argumenta que existiria uma elite que estaria enriquecendo à custa do "povo". Esta elite seria liberal,

\footnotetext{
${ }^{29}$ Trump perdeu no voto popular (diferença acima de 1 milhão de votos) mas ganhou no colégio eleitoral (diferença de 74 votos).
} 
multicultural bem exemplificada no casal Clinton e seus apoiadores como Warren Buffett, e outros da elite "cosmopolita" como Bill Gates, os editores do The New York Times ou jornalistas e mulheres em posição de destaque na mídia como Megyn Kelly (da Fox News), Rosie O’Donnell ou Rachel Maddow (da MSNBC).

Trump não demonstrou arrependimento e não se desculpou em nenhuma ocasião na qual esteve envolvido em trocas de ofensas com mulheres. E foram vários casos (além das acusações de assédio e estupro) e ao contrário, Trump mesmo quando na defensiva costuma atacar. No caso das mulheres recorre a adjetivos como "disgusting" "nasty" e "crooked". Nos termos de Kate Manne (2016) a duas formas clássicas de manifestação misógina seriam colocar as mulheres "para baixo", rebaixá-las, humilhá-las e a outra manifestação é o contrário ao avesso, colocar homens para cima, destacá-los, valorizá-los etc. A misoginia como nos mostra Judith Butler (2016) serve para manter a hierarquia de gênero.

Segundo análise de Kate Manne (2016) as mulheres incomodam Trump em duas situações, quando desafiam o poder dos homens, como faz, por exemplo, Hillary Clinton e neste caso elas são "gananciosas", "corruptas", "nazistas" ou quando se recusam a "servir", seja os homens em geral ou Donald Trump em particular. E neste caso entrariam Megyn Kelly, Rosie O’Donnell e Rachel Maddow. Neste caso, Trump as ataca as acusando de serem mulheres "frias", "egoístas”, "vagabundas", “feias”, "bruxas” etc.

Trump ataca as mulheres se afirmando tanto como um anti-establishment, que não teme o politicamente correto mas se coloca como um líder, um patriarca que fala as mulheres em tom paternalista. Como lembra Manne (2016), as mulheres tem uma importância na vida e na carreira de Donald Trump, mas sempre como a "mãe amorosa", a "boa esposa", a "namorada badalada e desejada" ou na figura da "secretária leal e competente". De certa forma esta retórica ecoa em parte do eleitorado masculino que tem chefes mulheres ou que trabalha com mulheres competitivas, solteiras ou mesmo não interessadas em relacionamentos heterossexuais. Para este eleitorado, Trump promete "fazer a América Grande Novamente (para os homens)." Não surpreendentemente, Trump também teve grande e importante apoio nacional de mulheres. Desde figuras políticas nacionais como Sarah Palin e Ann Coulter até figuras históricas da luta anti-feministas como Phyllis Schlafly que apoiaram Trump. E na média nacional de votos, Trump teve segundo pesquisa da CNN, $41 \%$ do voto feminino.

Já a retórica que afeta os negros, Trump promete uma América que seja grande novamente para os Homens Brancos. Se muitos enxergavam em Barack H. Obama o início da "América pós-racial", Trump reafirma e quer mobilizar o eleitorado branco, principalmente de trabalhadores sem ensino superior que são contra ações afirmativas e que acreditam que o governo federal deveria priorizar eles, homens brancos desempregados ou em subempregos e não negros, latinos e mães solteiras que, nesta visão, seriam "preguiçosos" e querem ser "espertos" vivendo à custa do Estado. 0 imaginário das "cadillacs mom's", as "mães negras ou solteiras" que dirigiam cadillacs enquanto alegavam serem pobres para não trabalharem e continuarem a receber auxilio do governo é antiga. Foi usado com força 
por Ronald Reagan nas campanhas do final dos anos de 1970 e visava criar uma cultura política favorável aos cortes nos programas de Bem-Estar Social. Os neoconservadores também passaram a defender cortes sociais e influenciaram as políticas sociais de George W. Bush entre 2000 e 2008.

Trump também manipula a ideia de que negros são violentos e estão diretamente relacionados com os crimes principalmente os violentos que ocorrem nos EUA. Neste ponto Trump se parece com Nixon e literalmente fez referência a campanha de 1968 reciclando o discurso de "Lei e Ordem". Desta vez, Trump fala em "lei e ordem" contra movimentos como o Black Lives Matter, que faz protestos pacíficos denunciando a crescente de mortes de negros inocentes pela polícia. Trump aproveitou o medo disseminado a partir de eventos como a morte de 5 policiais por um atirador negro em Dallas. Outros eventos menores aconteceram em estados como Iowa, Tennessee e Geórgia.

Estes eventos produziram especulações inclusive da volta dos "Panteras Negras" e de grupos de terrorismo doméstico organizado por pessoas negras que teriam como alvo policiais brancos. O sentimento de volta do "conflito racial" ganhou dimensões ainda maiores no mundo virtual. Neste ponto é interessante notar como Trump não freio ímpetos racistas de autoritários que surgiram entre seus apoiadores e eleitores. Sites abertamente racistas passaram a apoiar Trump e produzir memes como o Trump como o Pepe, the Frog que por sua vez, passaram a ser replicados pelo próprio candidato e quando confrontado com o teor racista- não o próprio Trump - pessoas próximas como seu filho, Donald Trump Jr., alegaram desconhecer o conteúdo racista do meme. Apesar da retórica "lei e ordem" e de flertar muitas vezes abertamente com o racismo, Trump teve, segundo pesquisa da CNN, 8\% dos votos de todos os negros nos EUA, uma plataforma similar à conquistada por Mitt Romney que em 2012 enfrentando Barack Obama teve 7\% do voto dos negros.

A mesma lógica se aplica aos latinos. A campanha de Trump os associa a crimes violentos, principalmente crimes sexuais e os considera bode expiatório para a crise mais ampla dos EUA. A diferença entre o "problema com os negros" e o "problema com os latinos" é de ordem demográfica.

Autores e personalidades políticas como Anne Coulter (2016) Pat Buchanan (2005), Tom Tancredo, Kris Kobach e o Xerife do Arizona, Joe Arpaio argumentam que os EUA sofrem uma espécie de "invasão dos bárbaros". Os latinos, especialmente os mexicanos, atravessariam as fronteiras (supostamente sem qualquer controle ou segurança) e uma vez nos EUA, seriam parasitas, viveriam sem se integrar (falam espanhol e não inglês), são violentos, machistas, católicos (e não protestantes) e segundo dados demográficos, passaram de $9 \%$ da população total em 1990 para 17\% em 2010 podendo chegar a 30\% em 2060. Mesmo os dados oficiais mostrando que nos últimos dez anos mais latinos saíram do que entraram nos EUA, a percepção de ameaça e medo aumentou. Apesar de foco e da retórica anti-latinos, Trump teve $28 \%$ de todos os votos de latinos segundo pesquisa da CNN, passando de 30\% em estados estratégicos como a Flórida. 


\section{ensaio}

O medo de uma islamização da América também aparece no discurso político de Donald Trump. Na cruzada anti-politicamente correta, o magnata de NY faz questão de enfatizar a existência de um "radicalismo islâmico" e de um "terrorismo islâmico" associações que Obama se recusaria fazer temendo ofender uma religião milenar e presente na vida de bilhões de pessoas. Trump argumenta que o islã é inimigo do modo de vida americana, usa os ataques em Orlando a uma boate Gay como exemplo, e de certa forma confunde refugiado com imigrante ilegal, reforçando que o muro na fronteira também protegeria os EUA de uma "invasão de refugiados muçulmanos". A ideia do islã como principal inimigo ideológico dos EUA aparece com ênfase nos discursos e ideias defendidas por alguns dos principais estrategistas políticos de Trump como o General Michael Flynn e o ex-editor do portal de notícias alt right, Stephen K. Bannon.

O sentimento de que os "brancos" serão minoria é um tema de mobilização histórica da extrema direita tanto nos EUA quando em todos os lugares do mundo, contudo nos EUA - e em torno da candidatura de Trump - o tema ganhou uma proporção que nenhum candidato atingiu nos EUA anteriormente. O lema "Make America Great Again" conseguiu mobilizar pela raiva tanto defensores abertos da supremacia racial como eleitores brancos frustrados que como num movimento nativista know-nothing sente-se acolhido por um movimento que promete voltar há uma sociedade idealizada economicamente, culturalmente e racialmente.

Da raiva contra as elites manipulando "conspirações"; do sentimento misógina contra as mulheres, manipulando o politicamente correto e multiculturalismo até o bode expiatório dos imigrantes latinos/ mexicanos, deste caldo de raiva surge um candidato populista, nem "pós-racial" nem "pós- feminista”, mas sim, que algumas vezes demonstra seu racismo e misoginia e que em muitas outras não os reprime nem aceita o debate.

\section{Conclusão: A manipulação do medo na era da pós-verdade divide (e enfraquece) os EUA.}

“Donald Trump, you're asking Americans to trust you with their future. Let me ask you, have you even read the United States Constitution?” Khizr Khan ${ }^{30}$

A vitória de Donald J. Trump em 08/11/2016 deixa o mundo em estado de perplexidade e nos EUA produziu uma reação imediata de revolta e de extrema ansiedade. Quem foram às ruas da Filadélfia, Portland, Dallas, Miami, Seattle, Nova Iorque e tantas outras cidades foram principalmente os jovens, os negros, latinos e muçulmanos. Interpretados pelos apoiadores - ou mesmo pelo próprio Trump - como "minorias", "manifestantes profissionais" ou "mal perdedores" o fato é que a motivos para revolta, indignação e, sobretudo para estarmos preocupados com o que poderá ser o governo Trump. Ex-primeiro ministro da Austrália, Tony Abbott ${ }^{31}$, fez boa síntese do significado da

\footnotetext{
${ }^{30}$ Cf. Embate entre Khizr Khan e Donald Trump em < http://www.usatoday.com/story/news/politics/ onpolitics/2016/08/01/trump-khan-feud-timeline/87914108/ > Acessado em 15/11/16.

${ }^{31}$ Cf. Entrevista original com Tony Abbott em <http://www.smh.com.au/federal-politics/political-news/ the-revenge-of-the-deplorables-tony-abbott-says-donald-trumps-victory-will-put-climate-change-in-bet-
} 
vitória de Trump: "Trata-se da revanche dos deploráveis. Todas as pessoas que cansadas de serem chamadas de racistas, sexistas, homofóbicas, islamófobicas, que não eram nem nunca foram "politicamente corretas". Todas estas pessoas se identificaram e votaram em peso em Donald Trump". Slavoj Žižek ${ }^{32}$ aponta para outro horizonte, mostrando que não se trata de uma debate sobre "politicamente correto", mas sim de problemas na "fábrica de consensos". Com Trump de fato os valores públicos americanos estão em risco. E o islã e sua relação com os EUA podem caminhar ou talvez voltar ao centro deste debate.

Como mostramos, Donald Trump tem uma habilidade excepcional de se comunicar e mobilizar apoiadores mesmo sem uma plataforma clara e mesmo sem qualquer experiência política ou preparo para pleitear o cargo de presidente dos EUA. Muitas vezes, falando de forma vulgar, Trump conseguiu mobilizar um eleitorado inédito pelo medo, pelo ressentimento flertando muitas vezes com teorias conspiratórias e alimentando paranoias.

Neste ponto, destaca-se como o islã como religião abstrata e os muçulmanos como ameaças reais foram centrais neste processo. De forma clara e se colocando como um líder populista - "eu sou sua voz" - como dizia muitas vezes em seus comícios, Trump primeiro criou entre seus seguidores a percepção de o "o islã nos odeia". Isso foi particularmente manipulado logo após os ataques a boate em Orlando que deixou 40 mortos em junho de 2016. Trump também defendia - como estratégia para combater o terrorismo - fechar mesquitas, principalmente na cidade de Nova Iorque ${ }^{33}$. Também entende que as mesquitas não deveriam ter o direito ao "chamado para as orações" uma debate que já ocorre, por exemplo, em Israel ${ }^{34}$.

Quando Trump falava de "Oriente Médio" principalmente relacionando com o Estado Islâmico (EI), a ênfase do bilionário de Nova Iorque era que tanto Obama como Hillary e o próprio partido Democrata seriam todos simpáticos ao islã - por isso não falariam em "radicalismo islâmico" e não teriam impedido o surgimento do EI.

Somado a tudo isso, Trump argumentava que ao receber refugiados ou imigrantes da Síria ou de países do Oriente Médio estariam assim como no caso dos latinos do México ou de toda América Latina, recebendo em seus termos "a lixeira dos problemas do mundo".

Asolução? Para Trump tudo é muito simples, basta impedir a entrada de muçulmanos nos EUA ${ }^{35}$, deportar os ilegais ou com alguma "ficha criminal" e avançar propondo um banco de dados para controlar todos os muçulmanos nos EUA ou em trânsito. Como fazer ter-perspective-20161116-gsr0yl.html> Acessado em 16/111/2016.

${ }^{32}$ Cf. Podcast de Slavoj Žižek no portal Big Think<http://bigthink.com/videos/slavoj-zizek-on-donaldtrump-presidency> Acessado em 20/11/2016.

${ }^{33} \mathrm{Cf}$. Trechos sobre este tema em <https://www.washingtonpost.com/video/politics/clips-from-breitbart-radio-show-reveal-trumps-relationship-with-stephen-bannon/2016/11/15/5854c606-ab89-11e68f19-21a1c65d2043_video.html> Acessado em 19/11/2016.

${ }^{34} \mathrm{Cf}$. em <http://www.nytimes.com/2016/11/17/world/middleeast/lod-israel-muslim-prayer.html>

${ }^{35}$ Proposta / ideia que surgiu em sua campanha em dezembro de 2015 e virou decreto presidencial em 27/01/2017 barrando a entrada de pessoas de 7 países (Irã, Iraque, Síria, Líbia, Sudão, Iêmen e Somália) por 90 dias. No mesmo decreto a entrada de refugiados ficou suspensa por 120 dias. Ver a ordem executiva na integra em <https://www.theguardian.com/us-news/2017/jan/27/donald-trump-executive-orderimmigration-full-text> Acessado em 06/02/2017. 
esse controle? Com rastreamento de identidade e forçando uma declaração religiosa em toda entrada e/ou saída dos EUA.

O muçulmano como "bode expiatório" - assim como o imigrante latino - manipula um dos medos mais comuns nos EUA nos últimos 100 anos, a ideia de um "inimigo" infiltrado que estaria pouco a pouco corroendo, destruindo, matando os EUA e seus valores. $\mathrm{O} \mathrm{Ku}$ Klux Klan (KKK) chegou a ter milhões de seguidores nos anos 20 manipulando o medo do fim da escravidão, dos católicos, judeus ou "estrangeiros" incompatíveis com o espírito genuinamente "americano". Além de assassinar, torturar e enforcar principalmente negros, o KKK também costumava queimar as igrejas dos negros.

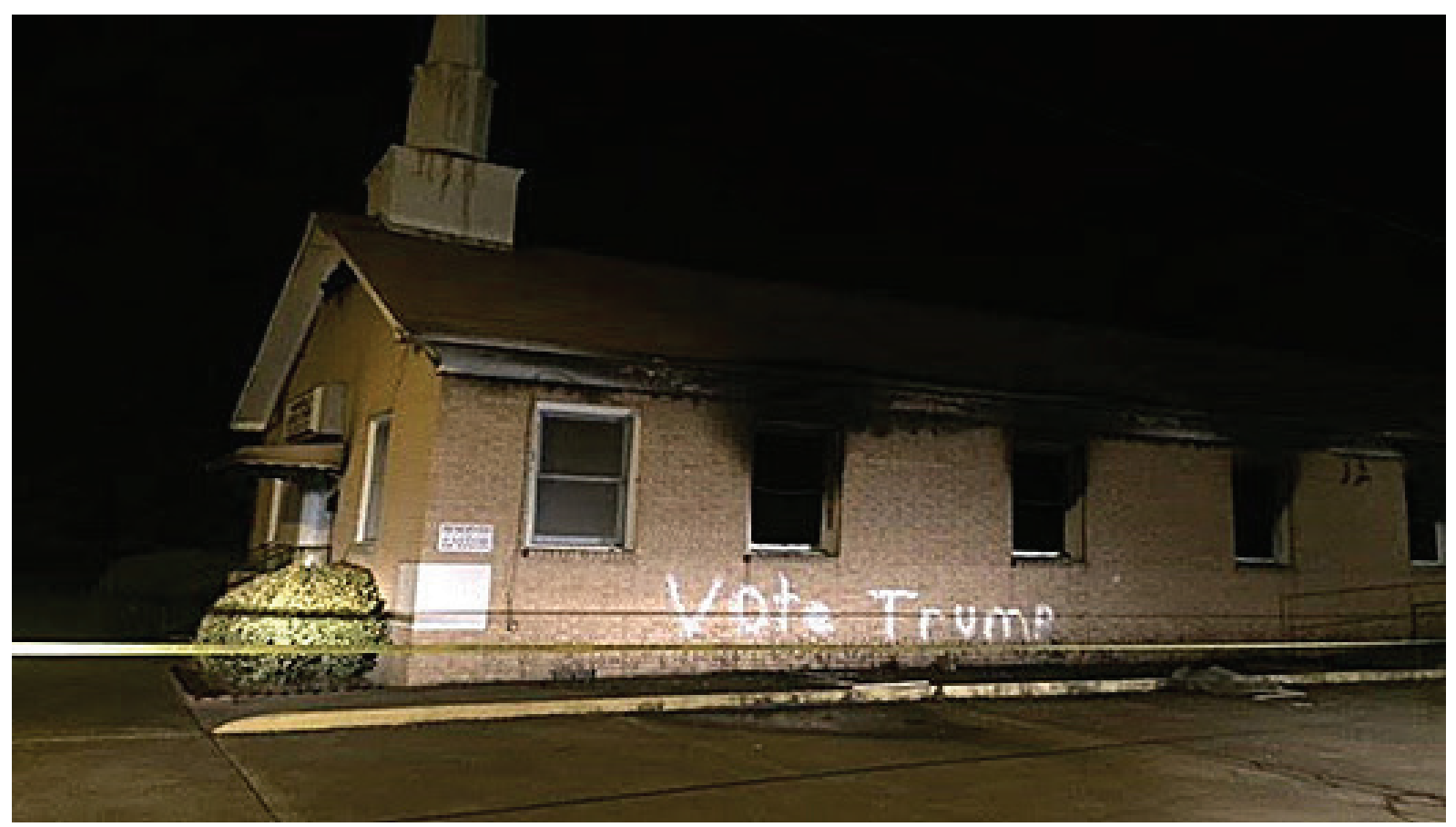

Fonte: AngieQuezada/ Delta Daily News

O senador Joseph McCarthy manipulou o risco da subversão e da espionagem comunista nos anos $50^{36}$. A John Birch Society nos anos 60 com a paranoia de "comunistas infiltrados no governo dos EUA ${ }^{37 "}$ teve milhares de seguidores. E mais recentemente, milícias e "movimentos patrióticos" se preparam para enfrentar o próprio governo federal que consideram despótico e controlado por forças estrangeiras.

A novidade trazida por Trump é que ele não representa nem responde a nenhum movimento ou se quer está num partido que enfatiza estas bandeiras, como no caso da Front National na França, notório pelas bandeiras anti-imigração e anti-islã a pelo menos quatro décadas. No caso do candidato americano, apesar do apoio que recebeu da KKK, ele alega desconhecer este e todos os demais grupos de extrema direita que o apoiam.

\footnotetext{
${ }^{36}$ Frases como "one communist is a communist to many" ou "better dead than red" ficarampopulares. E por coincidência ou não, um dos "mentores" de Donald Trump, é o advogado Roy Cohn, falecido em 1986. Cohn defendeu os interesses dos negócios Trump, mas antes trabalhou com Joseph McCarthy.

${ }^{37}$ Popularizaram expressões como "This is a Republic not a Democracy. Let's keep it that way. Ou "Get US out of United Nations."
} 
Contudo, ele se apresenta como uma espécie de "homem forte", alguém que não só chama o inimigo pelo seu nome - "o radicalismo islâmico" ou "Estado Islâmico" - como não hesitaria em usar de todos os meios, sobretudo de ir para o ataque, contra esses inimigos. Trump neste ponto em campanha dizia que acabaria com o EI, mesmo cogitando usar armas nucleares e novamente, a ideia de "barrar os muçulmanos". A retórica de Trump quer desmascarar, explicitar as ansiedades de uma sociedade desigual, tanto em termos de classe como de raça ou sexo/gênero. Como muitos observadores notaram durante a campanha, além de gritos pela prisão/morte de Hillary Clinton e pelo famigerado muro na fronteira com o México, se ouvia também gritos de ódio a muçulmanos e negros.

Quando Khizr e Ghazala Khan, os pais do soldado Humayun Khan morto servindo ao exército dos EUA no Iraque em 2004, questionaram em plena convenção democrata os "valores" de Trump, sua resposta semanas depois foi atacar Ghazala Khan, que para Trump nada disse, pois no islã mulheres não tem voz. Muitos se ofenderam com a reação do candidato republicano - muitos dentre seus próprios correligionários - o que o levou a enfatizar que se ele, Trump, fosse o presidente antes, a família Khan não teria perdido seu filho pois ele seria contra a guerra do Iraque. Mesmo assim não recuou da ideia de "barrar os muçulmanos" até saber, em seus termos, "o que esta acontecendo".

Questionado se não estaria sendo "selvagem" ao propor barrar os muçulmanos ou "liquidar o EI", Trump prontamente respondeu que era preciso jogar "o jogo que eles jogam" e que "seremos selvagens se isso acabar com os selvagens". Em uma frase, na sua já conhecida vulgaridade, "Bomb the shit out of them". Neste ponto é também curiosa - e inédita - a simpatia e promessa de alimento que Trump sinaliza entre EUA e Rússia. Tal como Vladimir Putin, Trump parece ser um crítico da Aliança para a Organização do Tratado do Atlântico Norte (OTAN), e sinaliza para uma retirada do apoio dos EUA. No terceiro debate presidencial ${ }^{38}$, Trump afirmou que a "Síria era a Rússia e a Rússia estava acabando com o Estado Islâmico" e que, portanto, os EUA deveriam apoiar este tipo de iniciativa e não eventualmente tirar Bashar al-Assad - como indiretamente argumentava Hillary Clinton.

Trump não fez uma oposição conservadora às propostas de Clinton. Sua agenda se mostrou algo hibrido misturando posturas pró-Rússia - como no caso da Ucrânia - e disposição a valorizar novos aliados como a Turquia de Recep Tayyip Erdoğan, a Inglaterra "pós-Brexit" de Theresa May; além de sinaliza punir novos inimigos de Moscou, como o Irã, cujo acordo nuclear considerado um dos legados de Obama poderá ser revisto, algo que pode ser também bem visto por Israel de Benjamin "Bibi” Netanyahu. Um dos principais assessores de Trump na transição e também no início da gestão é o general Michael T. Flynn ${ }^{39}$, militar aposentado em 2014, que terminou sua carreira trabalhando na Inteligência do Pentágono. Segundo Kitfield ${ }^{40}$, Flynn foi um dos generais responsáveis pelos interrogatórios realizados pelos EUA na Guerra contra o Terror dos anos George

\footnotetext{
${ }^{38}$ Cf. Debate em <https://www.youtube.com/watch?v=dGQGwIr47YY> Acessado em 16/11/2016.

${ }^{39}$ Escolhido como Assessor Nacional de Segurança.

${ }^{40}$ Cf. a discussão de James Kitfield sobre o general Michael T. Flynn em <http://www.politico.com/magazine/story/2016/10/how-mike-flynn-became-americas-angriest-general-214362>
} 
W. Bush. O ponto central para o general seria que o terrorismo islâmico é ideológico e, portanto, a estratégia de Obama de derrotar os terroristas militarmente não produziria uma redução do terrorismo. Ao contrário, para Flynn, o objetivo seria derrotar a Al Qaeda do Paquistão cada vez mais descentralizada e presente em mais países. Assim, a ameaça terrorista da era Obama seria maior que antes e o medo em relação aos muçulmanos seria algo racional ${ }^{41}$. Curioso destacar que Flynn foi um dos primeiros estrategistas de Trump a cair. E teve que pedir demissão justamente num escândalo ${ }^{42}$ envolvendo um triangulo entre o embaixador russo nos EUA, o general Flynn e o vice presidente, Mike Pence.

A sensação de vulnerabilidade diante do terrorismo islâmico é explorada pelo candidato/presidente Donald Trump. Tal como Putin, Trump acredita que suas ações são validas uma vez que está em "combate ao terrorismo" e "defendendo sua pátria". E em nome de um nacionalismo tradicionalista, Trump em 26/01/2017 decretou que pessoas vindas de países muçulmanos, mais especificamente do Iraque, Líbia, Somália, Sudão, Síria, Iêmen e Irã, com ou sem visto americano, em conexão ou não, refugiados ou imigrantes, independentemente de qualquer contexto (político, médico ou humanitário) não entrariam mais nos EUA. A decisão dividiu a opinião pública (49\% aprovaram) e muitos de dentro da maquina estatal se rebelaram contra a decisão e protestos internacionais e por todo o EUA levaram a decisão a ser amenizada menos de uma semana depois. A decisão de Trump, segundo analistas, deve ser credenciada ao assessor político, Stephen K. Bannon, um dos principais articuladores da chamada alt right. Para Bannon, é preciso pensar o sentido de nação e por isso a necessidade de delimitar quem pode entrar e ficar nos EUA. Ao barrar a entrada de pessoas destes sete países, Bannon acredita - e convenceu Trump - que os EUA estariam assim mais seguros selecionando de forma qualitativa quem poderia entrar ou passar pelos EUA.

A imagem "de força e ação" contra os inimigos e de nacionalismo e patriotismo é especialmente atraente num discurso que tenta manipular particularmente a classe trabalhadora. Apesar de ter levado uma vida que só os $1 \%$ mais ricos poderia arcar, Trump tentou e conseguiu estabelecer alguma empatia com a "classe trabalhadora branca e masculina". Citou muitas vezes Bernie Sanders, apresentado como um "socialista”, e suas falas em comícios, eventos de campanha em geral começavam com a evocação "Folks". Como trabalhadores em um sindicato, Trump dizia de como as coisas iam "bad, bad not good" para, em seguida, defender a ideia de "American first" e no auge ele conseguia levar o público a acreditar que ele, Trump, conhecia o sistema então só ele, ou talvez ele melhor do que qualquer outro, poderia resolver todos os problemas e acabar de uma vez com todos com o atual "establishment" entendido como "liberal", "corrupto", "sujo" e "antiamericano" 43 .

\footnotetext{
${ }^{41}$ A declaração literal ocorreu em post no Twitter, conferir revisão deste material em <https://www.washingtonpost.com/news/checkpoint/wp/2016/11/18/trumps-new-national-security-adviser-has-said-some -incendiary-things-on-the-internet/> Acessado em 20/11/2016.

${ }^{42}$ Flynn teria se encontrado com o embaixador russo , trocado informações que por sua vez não foram passadas para o vice presidente.

${ }^{43}$ A ideia de que um "establishment liberal" está destruindo os EUA é debatido a pelo menos 20 anos. Alguns autores famosos deste debate nos EUA são: Robert Hughes, Tyler Cowen, Charles Murray e Arthur Herman.
} 
Trump também passa tempestividade, como alguém de confia em instintos e que tem autoconfiança. Ao contrário de tantos outros presidentes como John F. Kennedy ou George W. Bush que se orgulhavam de "decidir" depois de consultar os "melhores e mais brilhantes", Trump sinaliza que não precisara mais do 5 segundos para tomar decisões e se considera a si como a principal referência ${ }^{44}$. Esse perfil tempestuoso funciona muito bem com uma plataforma populista e teve êxito e impacto especial na campanha via internet. Principalmente nas redes sociais e em particular no Twitter e seus 140 caracteres. Foi através do Twitter que Trump mostrou-se como capaz de se comunicar com milhões e de traduzir - em poucos caracteres - suas aspirações, ideias e dar voz aos medos e as ansiedades de seu eleitorado. 0 êxito online de Trump ocorreu paralelamente ao também êxito da chamada alt right. Tanto o candidato Trump como a alt right questionam o mainstream da opinião pública, tanto conservador como liberal, tanto de direita quanto de esquerda. A alt right representa velhas bandeiras da extrema direita, a questão racial, o antissemitismo etc, mas o faz em linguagem contemporânea com memes, com trending topics no Twitter e com exércitos de trolls, muitas vezes controlados por poucos mas que fazem o estrago de um exército. Trump se beneficiou desta batalha promovida pela alt right e afirma-se como anti-establishment. Em suas palavras ${ }^{45}$ :

$\mathrm{Eu}$, da minha parte, não estou interessado em defender um sistema que há décadas serve, à custa do povo, ao interesse dos partidos políticos. Há um clube - formado por consultores, pesquisadores, políticos, especialistas e os grupos de interesses - que apenas ficaram mais ricos e poderosos enquanto o povo americano se torna mais pobre e isolado.

Sem um programa de governo claro e estruturado, a candidatura Trump - e seus primeiros dias como presidente - apresentam slogans, frases e propaganda como se fossem plataforma de governo. Seguindo a tradição dos movimentos "KnowNothing", Trump construiu uma campanha e conquistou uma vitória - com mais de 60 milhões de votos - com base na manipulação do medo e com propaganda e slogans, o mais notório sem dúvida o "make America great again!"6" .

Em sua campanha Trump deu uma nova dimensão, agora "mainstream", a uma

\footnotetext{
${ }^{44}$ Em entrevista a rede MSNBC quando perguntado quem ele consultava quando o tema era política externa, Trump respondeu: "First I speak to myself". Cf. em <https://www.youtube.com/watch?v=W7CBp8lQ6ro>. Acessado em 16/11/2016.

${ }^{45}$ No original: I, for one, am not interested in defending a system that for decades has served the interest of political parties at the expense of the people. Members of the club-the consultants, the pollsters, the politicians, the pundits and the special interests-grow rich and powerful while the American people grow poorer and more isolated. Cf. integra do texto opinativo escrito por Trump para o Wall Street Journal em abril de 2016, em :<http://www.wsj.com/articles/let-me-ask-america-a-question-1460675882>

${ }^{46}$ Jornalista do The Washington Post perguntou para diferentes pessoas o que elas entendiam por " Make America Great Again!" e as respostas foram das mais variadas possíveis . Cf. em<<iframe width='480' height='290' scrolling='no' src='https://www.washingtonpost.com/video/c/embed/6e35851a-4fa811e6-bf27-405106836f96' frameborder='0' webkitallowfullscreenmozallowfullscreenallowfullscreen $><$ / iframe>. Acessado em 20/11/2016. E mal Trump tomou posse, já lançou o mote para a reeleição: "Keep America Great". Cf. <https://www.washingtonpost.com/news/the-fix/wp/2017/01/18/donald-trumpsnew-2020-campaign-slogan-is-very-well-donald-trump/?utm_term=.c4db8d9e7556> Acessado em $06 / 02 / 2017$.
} 


\section{ensaio}

série de "raivas reprimidas" nos termos de Judith Butler ${ }^{47}$. Se apoiando, por exemplo, em notícias de sites como o Breibart ${ }^{48}$, InfoWars ${ }^{49}$ que misturam teorias conspiratórias com propagandas racistas e formato sensacionalista, e se apropriando de expressões e termos de figuras notórias da extrema direita como David Duke (ex-KKK) ou mesmo divulgando material abertamente racista de sites de defensores da supremacia racial/neonazistas ${ }^{50}$. Trump demonstra não só manipular o medo e o ressentimento mas também resgata e reabre a ferida racial, afirmando - ou pelo menos manipulando - a tese que os "brancos" seriam vítimas tanto da violência dos negros (no contexto da emergência do movimento Black LivesMatter) como da "cultura do estupro" dos latinos ou do ódio dos muçulmanos.

Agora eleito, muitos analistas querem acreditar que "tudo vai ser diferente". A conta de Trump do Twitter foi substituída por uma do agora "presidente Trump". Suas primeiras declarações pós-eleição foram pedindo "união" e condenando manifestações violentas (tanto de seus apoiadores como dos críticos). Não se trata de pessimismo, mas dificilmente um populista consegue manter sua legitimidade intacta sem decepcionar muito ou pouco - seus seguidores. A questão é que sempre decepciona. Como estes "decepcionados" reagirão é uma incógnita tão grande quanto a própria presidência de Donald J. Trump.

O islã e a comunidade muçulmana nos EUA podem periodicamente servir como "bodes expiatórios" sempre que o equilíbrio populista mostrar-se desfavorável a Donald J. Trump. Como os conservadores, liberais ou libertários reagirão a tal estratégia é algo que devemos estar atentos. Nunca é demais lembrar Jürgen Habermas ${ }^{51}$ : "em um mundo acometido pelas irracionalidades" precisamos nos perguntar se de fato "aprendemos algo com as catástrofes" e não normatizar a exceção sob o risco de não recuperarmos mais os valores públicos, cuja fábrica, nos termos de Žižek, está quebrada. E vale notar que as vésperas de assumir, entre o final de 2016 e começo de 2017, segundo dados oficiais ${ }^{52}$, crimes de ódio contra muçulmanos nos EUA estavam novamente em seu pico, tal como o atingido logo após os ataques de 11/09/2001. "Dividir para Governar", talvez seja este o verdadeiro slogan de Trump - e os "fatos alternativos" apenas instrumentalizam esta estratégia.

\footnotetext{
${ }_{47}$ Cf. <https://blogdaboitempo.com.br/2016/11/11/judith-butler-quem-sao-os-eleitores-de-trump/ > Acessado em 15/11/2016.

${ }^{48}$ Trump já convidou o presidente deste site e chefe da campanha presidencial, Steve Bannon para seu time de transição.

${ }^{49}$ Cf. < http://www.infowars.com/ >. Acessado em 15/11/2016.

${ }^{50}$ Vale destacar que Trump conseguiu impactar na própria dinâmica das grandes redes de notícia dos EUA. A Fox News, líder de audiência no segmento desde o 11/09/2001, perdeu a liderança. Portais de noticias online mais populistas como DrudgeReport voltou a aparecer entre os mais acessados e procurados na internet.

${ }^{51}$ Cf. Texto de Vanessa Capistrano sobre Habermas em < http://neai-unesp.org/jurgen-habermas-conversasobre-filosofia-comunicacao-e-esfera-publica/ > Acessado em 15/11/16.

52 Cf. Pesquisa em <http://www.pewresearch.org/fact-tank/2016/11/21/anti-muslim-assaults-reach-911-era-levels-fbi-data-show/?utm_source=Pew+Research+Center\&utm_campaign=9e40b867cf-Weekly_Nov_23_201611_22_2016\&utm_medium =email\&utm_term=0_3e953b9b70-9e40b867cf-399749197> Acessado em 23/11/2016.
} 


\section{Referências Bibliográficas}

ARENDT, Hannah. Verdade e Política. Tradução de Manuel Alberto. São Paulo: Abdet, 1967. Disponível em: < http://abdet.com.br/site/wp-content/uploads/2014/11/ Verdade-e-pol\%C3\%ADtica.pdf>. Acessado em: 17 de janeiro de 2017.

BAGGIO, Antonio M. Verdade e Política. Tradução de José Maria de Almeida. São Paulo: Revista ABBA, Volume III - ano 2000 N2. Disponível em: <http://www.mppu.org.br/ novo/download/pdf/verdade_e_politica.pdf>. Acessado em: 15 de janeiro de 2017.

BUCHANAN, Patrick J. The Death of the West: How Dying Populations and Immigrant Invasions Imperil Our Country and Civilization. Ed. St. Martin’s Griffin, NYC. 2002.

Where the Right Went Wrong: How Neoconservatives Subverted the Reagan Revolution and Hijacked the Bush Presidency. Ed. St. Martin's Griffin, NYC. 2005.

NYC. 2012.

Suicide of a Superpower: Will America Survive to 2025? Ed. St. Martin's Griffin,

CANAVIlHAS, João. A Comunicação Política na Era da Internet. Lisboa: Biblioteca Online de Ciências da Comunicação (BOCC), 2009. Disponível em: <http://www.bocc.ubi. pt/_esp/autor.php?codautor=602>. Acessadoem: 15 de fevereiro de 2017.

CARLSON, T.; DJUPSUND, G. Old Wine in New Bottles?The 1999 Finnish Election Campaign on the Internet.Harvard International Journal of Press Politics, 6 (1), 2001.

CASSIDY, John. Trump's Challenge to American Democracy. Nova York: The New Yorker, 29 de novembro de 2016. Disponível: <http://www.newyorker.com/news/john-cassidy/ trumps-challenge-to-american-democracy>. Acessado em: 15 de janeiro de 2017.

COLTER, Ann. In Trump We Trust: E Pluribus Awesome! Ed. Sentinel, NYC. 2016.

. Adios, America: The Left's Plan to Turn Our Country into a Third World Hellhole. Ed. Sentinel, NYC. 2016.

DORIA, Pedro. Trump e a pós-verdade. 0 Globo. Economia, 18 de novembro de 2016. Disponível: < http://oglobo.globo.com/economia/trump-a-pos-verdade-20484416> Acessado em: 15 de janeiro de 2017.

ECONOMIST. Editorial. Fev. 2017. Disponível em < http://www.economist.com/news/ business/21717107-making-americas-august-news-groups-great-again-traditionalmedia-firms-are-enjoying-trump-bump > Acessado em 22/02/2017.

ENGLISH OXFORD LIVING DICTIONARIES. Word of the Year 2016 is.... Disponível em: <https://en.oxforddictionaries.com/word-of-the-year/word-of-the-year-2016> Acessado em: 16 de janeiro de 2017.

ESTADÃO. 'Pós-verdade' é eleita a palavra do ano pelo Dicionário Oxford. 16 de novembro de 2016. Disponível em: <http://www.estadao.com.br/noticias/geral,pos- 
verdade-e-eleita-palavra-do-ano-por-dicionario-oxford,10000088825>. Acessado em: 16 de janeiro de 2016.

FELLET, João. Como a guerra ao 'politicamente correto' explica ascensão de Trump. BBC Brasil. 09 de março de 2016. Disponível em: < Como a guerra ao 'politicamente correto' explica ascensão de Trump> Acessado em 15 de janeiro de 2017.

GARSCHAGEN, B. Trump e a "política da pós-verdade". Gazeta do Povo. 28 de novembro de 2016. Disponível em: < http://www.gazetadopovo.com.br/opiniao/colunistas/brunogarschagen/donald-trump-e-a-politica-da-pos-verdade-dakbk0mjfr62ka408bm407snh37923743> Acessado em 15 de janeiro de 2017.

HOFSTADTER, Richard. The Age of Reform. Ed. Iaca House, NYC. 1960.

Anti-Intellectualism in American Life. Ed. Vintage, NYC. 1966.

The paranoid style in american politics. Harpers Magazine, 1964. Disponível em < http://harpers.org/archive/1964/11/the-paranoid-style-in-american-politics / > Acessado em 15/125/2016.

KENNEDY, Paul. The Truth about "Post-Truth". Ideas. CBC Radio-Canada. 19 de janeiro de 2017. Disponível em: <http://www.cbc.ca/radio/ideas/the-truth-about-post-truth-1.3939958>. Acessadoem 28 de janeiro de 2017.

LICHTMAN, Allan. White Protestant Nation: The Rise of the American Conservative Movement. Ed. Grove Press, NYC. 2009.

MANNE, Kate. The Logic of Misogyny.Boston Review, Julho de 2016. Disponível em <http:// bostonreview.net/forum/kate-manne-logic-misogyny> Acessado em 15/12/2016.

$\mathrm{OH}$, Inae. Donald Trump Is Building a Team of Fake-News Lovers and Conspiracy Theorists. Mother Jones. 06 de dezembro de 2016. Disponível em: < http://www. motherjones.com/politics/2016/12/trump-fake-news-michael-flynn-pizzagate>. Acessado em 15 de janeiro de 2017.

THE ECONOMIST. Post truth: Art of the Lie. 10 de setembro de 2016. Disponível em: <http://www.economist.com/news/leaders/21706525-politicians-have-always-lied-does-it-matter-if-they-leave-truth-behind-entirely-art>. Acessado em 15 de janeiro de 2017.

TURRER, Rodrigo; PEROSA, Teresa; MORRONE, Beatriz. 0 risco Trump. Época. 27 de julho de 2016. Disponível em: <http://epoca.globo.com/tempo/noticia/2016/07/o-riscotrump.html>. Acessado em 15 de janeiro de 2017. 